\title{
Portfolio as a Tool for Self- Reflection and Professional Development for Pre-Service Teachers
}

\author{
Arlinda Beka \\ Faculty of Education, University of Prishtina 'Hasan Prishtina', Kosovo \\ https://orcid.org/0000-0002-9871-783X \\ Ganimete Kulinxha \\ Faculty of Education, University of Prishtina 'Hasan Prishtina', Kosovo \\ https://orcid.org/0000-0003-4461-8841
}

\begin{abstract}
Self-reflections, especially those done through the usage of portfolios, are an essential component of teaching. Portfolio reflections allow pre-service teachers to set professional goals. This research was conducted using qualitative methodology, and all semi-structured interviews were organised with students and graduates from the Early Childhood Department-Faculty of Education, University of Prishtina. The research results show that a portfolio provides future teachers with the opportunity to organise their work better while enabling cooperation between pre-service teachers, which ergo, directly affects their professional competencies. Owing to its benefits, portfolio should be integrated by the Faculty of Education of the University of Prishtina as an integral part of its work with students.
\end{abstract}

Keywords: portfolio; pre-service preschool teachers; teacher professional development

\section{Introduction}

Self-reflection is one of the most important competencies that a teacher should possess. Reflection directly enables the identification of things that not only are a strong part of professional work but that also need to be advanced and to allow a higher level of professionalism. In terms of taking individual responsibility for thought and action processes, self-reflection is a required condition for assessment and regulation (Dilger, 2007). After completing a given task, one tries to reflect on the process and the work accomplished; however, sometimes one's attention is drawn to the sections that have been the most successful or most challenging, leaving out many other aspects that may be equally important for enhancing the quality of one's work and for continuing professional development.

Portfolios are a proper way of recording our accomplished work and the challenges and successes encountered during the process. The record of such data 
allows one to go back in time to see what one went through, how one did one's activities, how one conceived things or what challenges were faced during a given period. The portfolio technique is viewed as particularly huge with regard to selfintelligent learning. The technique forms a significant part in the advancement of polished skill through reflection and self-reflection (Riebenbauer, Dreisiebner \& Stock, 2017).

Through the use of portfolios, pre-service teachers can succeed in developing a professional working plan, reflect on their work, develop additional skills in the use of technology for professional development and have a clear review of their work (Beka \& Gllareva, 2016). Portfolios for self-reflection in pre-service teacher training provide vital input for trainers since they represent both the strengths and weaknesses of students (Cimermanová, 2019).

Portfolios play a significant role in not only the process of preparing teachers for employment but also in their licensing as teachers and coaches and their statelevel performance appraisals. Being reflective is a key aspect of any educational experience. It involves the continuous educational growth of both professional educators and students (Webster \& Whelen, 2019).

However, portfolio is often regarded as a collection of facts and documents that testify teachers' professional development and achievement. In some cases, it is considered as an important part where the teacher must present the work planned for certain periods, including the reflection on commitments which he/she has accomplished. Therefore, the teachers make the portfolio in terms of the purpose that it will serve them. Similarly, during pre-service studies, future teachers are sometimes required to have more reflections on their portfolio. In some cases, their portfolio is also required to include facts, arguments and goals that students aim to achieve during their studies (Stock \& Winkelbauer, 2012).

\section{Development of portfolios and the arguments}

The use of portfolios in pre-service teachers' professional development and professional assessment has become widespread around the world. As a result, several contemporary studies and research projects are being conducted by various scholars and educational scientists regarding the importance of portfolios, their meaning and their relevance to teachers' professional development. It is often thought that portfolio has begun to be affirmed in the last two decades as a contemporary approach to professional development. Portfolio, as a concept in education, has been developed in the last decades of XX century in the United States of America and the German-speaking countries (Slepcevic-Zach \& Stock, 2018).

For a clear understanding of the concept of portfolio usage among teachers whether in pre-service or in-service, we need to determine the purpose of the portfolio and the way in which it acts as a professional aid to the teacher. According to various authors, there is a discrepancy between the portfolio and the way it should be filled in, i.e., whether the portfolio will focus more on reflection or on the documentation of professional work. 
In his paper, 'Do Portfolios Have a Future?', Driessen (2017) divides portfolio into two categories, namely reflective portfolios and comprehensive portfolios. Reflective portfolio is primarily intended to help students improve their reflective abilities. It requires students to write a reflection on an aspect of their learning or career that is significant to them. Reflections can be found in comprehensive portfolios, but their material is much more varied than that of reflective portfolios (Driessen, 2017). Baumgartner (2009) classifies portfolio into the three following types depending on their purpose: reflection portfolio, development portfolio and presentation portfolio. The e-portfolio is a flexible tool that can be used for several purposes, including learning, evaluation/assessment and employability/career growth (Ciesielkiewicz, 2019). Trávníčková and Puhrová (2020) state that portfolios can be encountered in the following terms: 'professional teaching portfolio', 'professional development portfolio', 'professional practice portfolio' and even the relatively new term of 'eportfolio'.

All the above types of classifications from different authors can be considered as being similar due to their common elements. The reflective portfolio, which is considered a crucial part of teachers' professional development, is common in the classifications. The aim of comprehensive portfolios is to assist students in their learning and to evaluate their progress. Reflections can be found in comprehensive portfolios, but their material is much more varied than that of reflective portfolios (Driessen, 2017).

Since education methods, such as reporting, contemplation and representation of one's learning activity, were major issues in the 1980s, the portfolio idea might have been a pillar in the German debate about educational reform (Häcker, 2009). Like in Germany, in almost all European countries and beyond, the portfolio is beginning to be considered a significant part of pre-service and pre-service teacher work. Nowadays, portfolios are seen as

"rich, contextual, highly personalised documentaries of one's learning journey." (Jones \& Shelton, 2011, p.21).

There are numerous reasons why a portfolio is considered an important tool for teacher development and professional development. Portfolios are considered beneficial for pre-service and in-service teachers

"as they promote autonomous learning and autonomous learners are often motivated and reflective learners." (Fernández, 2014).

In almost all professions, especially the teaching profession, reflection is a crucial part. According to Lynch (2000), reflection is considered to be an important part of a person's skill set. Through reflection, each teacher undergoes a long and complicated process to reach his/her desired stage of professional development. Within the scope of the portfolio-work, not only the result (item) is critical but mostly the method that led to this improvement (Kerr, 2007). Therefore, the documentation of professional experiences through the use of a portfolio is an asset for every pre-service teacher. Usually, the portfolio's documentation is structured and deliberately designed as

"they contain purposefully organised documentation that demonstrates specific knowledge, skills, dispositions, and accomplishments achieved 
over time. Portfolios represent connections made between actions and beliefs, thinking and doing, and evidence and criteria. They are a medium for reflection through which the builder constructs meaning, makes the learning process transparent and learning visible, crystallises insights, and anticipates future direction." (Jones \& Shelton, 2011, p.22)

Despite the different definitions of portfolio which depend on their purpose, objective and nature, certain theories consider portfolio as a personal ownership, personal record structured collection of material and so on. According to Paris and Ayres (1994),

"The overarching purpose of portfolios is to create a sense of personal ownership over one's accomplishments because ownerships engender feelings of pride responsibility and dedication (p.10)."

McKimm (2014) defined teaching portfolios in her book 'A Handbook for Teaching \& Learning in Higher Education' as

"A teaching portfolio (sometimes referred to in this chapter as a 'portfolio') is a personal record of achievement and professional development as a university teacher. It is a carefully selected and structured collection of material that may demonstrate a level of attainment, a range of skills and activity, and/or progression.(p.473)"

Kayler (2004) states that:

"Teacher education institutions need to make the often-invisible professional growth of classroom teachers more visible to other teachers and programs as a way to foster and expand the teacher knowledge base (p.267)."

According to Fernández (2014), portfolios play a significant role in stimulating and inspiring teachers as well as students. Learning becomes more effective and motivating with a portfolio since the students take ownership of their learning process and develop strategies to plan, monitor and evaluate their learning. Teachers benefit from portfolios in their professional development since portfolios promote autonomous learning, and autonomous learners are often motivated (Fernández, 2014). Portfolios can also be considered as a source of data, whether qualitative or statistical, and are an important tool for evaluation.

In terms of assessment, Belgrad, Burke and Fogarty (2008) consider that portfolios (and e-portfolios) can become excellent tools for both, formative and summative assessments. Martin-Kniep (1999) considers portfolios as an instrument that recounts the account of the educator whose objective is to make guidance and evaluation rehearses something very similar and focused on critical learning results. The portfolio uncovers the educator's extraordinary capacity to apply educational plan and appraisal-related ideas and abilities to the advancement of exercises and evaluations that target obviously characterised results. The instructor has provided all drafts of appraisals, enabling the user to notice the changes and upgrades made to apply plan standards and better adjust educational program, guidance and evaluation. The teachers can utilise their portfolios to report their expert history, the inquiries and worries that drive their 
work, their endeavours to plan or carry out better or diverse learning encounters for understudies, their investigation of basic issues with at least one understudy or the settings that encompass them, their expert work with partners, local area individuals or bosses and their examination of and reflection on proficient assets or critical writings. Notwithstanding the specialised parts of portfolios, it should be remembered that the

"essential crowd for an educator portfolio is the instructor who readies the portfolio. Simultaneously, the portfolio can help instructors screen the change from the exercise as-wanted to the exercises educated, to the exercise as-learned. At last, portfolios can help screen educators' endeavours to fuse new information and abilities into their expert collections. Albeit quite a bit of this work is a private undertaking, educators, as different experts, need to take part in a discussion with their partners to really comprehend and approve their work. Portfolios can fill in as a springboard for such conversations." (Martin-Kniep, 1999, p.15)

This is very well explained in 'The Portfolio Connection: Student Work Linked to Standards', in which Belgrad et al. (2008) states that:

"Portfolios as the outcome of a continuous, student-centred process help students learn in a variety of ways. One remarkable by-product of the portfolio process in the classroom is increased student awareness of and responsibility for learning objective (p.15)."

The portfolio presents pre-service teacher's information that is directly related to the personality, mindset, worldviews, mission and vision approaches that preservice and in-service teachers create for themselves, whether on a personal or professional level. Portfolio creation represents the nature of the individual's personality, his/her level of knowledge and the goals that he/she wishes to achieve in his/her professional field.

This approach will help teachers in their awareness of professional development. They will manage to present the goals for their work and the path that they will follow. Moreover, portfolios will act as an open statement that they will follow to be more successful. In this way, they manage to develop critical thinking about themselves and their profession and begin to be more creative regarding their plan to achieve their professional goals. They also become aware of a sustainable professional investment that will serve their work in the long term. The portfolio also presents the skills that pre-service teachers have built up during their studies and becomes a bridge between them and the work that they will aspire to have, which enables teachers to have personal and professional competence.

Through reflective learning, pre-service teachers can learn from their previous experiences either in cognitive or practical terms, enabling them to make decisions for change and professional development. Pre-service teachers can also share information with their peers and obtain feedback from their colleagues, thus having an excellent opportunity to be open to others, share ideas and collaborate in the professional field. 
Creating a portfolio during the study period enables pre-service teachers to establish a culture of presenting ideas, approaches and understandings in the personal and professional field. By establishing strategies for presenting their work in a broader professional environment, they continue to present their work in the same way when they look for a job or even after they are hired. For teachers in the portfolio, a service is a great tool that can serve them for the evaluation performed either by their institution or even at a wider level.

Therefore, in terms of teacher professional development, regardless of in-service or pre-service teacher training, portfolio is a considerable tool for documentation, assessment and evaluation of instructors' work. They can be pre-designed and pre-structured to collect and document information as required for a specific task or profession, i.e., pre-service or in-service teaching. Portfolios enable teachers to document the evolution of different areas of their work, such as curriculum and assessment development, professional development, inquiry/research and teaching and learning in general.

When used by students, portfolios are developed to display materials that represent the abilities and accomplishments during a specified period. According to Henderson, Davis \& Day (2015), students' presentation of materials over an extended time helps to chronicle their improvement and competence that cannot be measured by paper and pencil tests. One of the primary purposes of a portfolio is to provide a more reliable and comprehensive picture of student growth and achievement.

By using pre-service teachers' portfolios, instructors will have better opportunities for their personal and professional development and will create a professional culture for their work with children. In Kosovo, as in several other nations, one of the vital competencies of instructors is to reflect on the work they do, to archive their completed exercises and to show the goals they wish to attain in a given period. Typically, the employment of a portfolio plays a critical role in teacher instruction in Kosovo or any other nations because it makes a difference in creating the key competencies for educator teachers and pre-service instructors (Beka, 2015).

According to the implemented laws and educational policies, all the pre-service and in-service teacher trainings in Kosovo are organised by public universities, particularly by their faculties of education (Ministry of Education, Science and Technology [MEST], 2011). The Faculty of Education of the University of Prishtina, being the oldest one, carries out the most significant role in teacher training. It provides pre-service and in-service teacher programs from undergraduate to doctoral level (University of Prishtina, 2004).

As part of the Strategic Development Plan of the Faculty of Education, improvement of quality teaching programs and teacher professional development are considered crucial factors for enhancing our education system (Faculty of Education, 2013). Professional portfolios of pre-service teacher are becoming now an integrated part of the teaching curriculum in all of its study programs. The Faculty of Education has had in the past few years several in-service training 
programs for teachers' professional development besides the regular study programs. Those programs have been supported by the MEST and different donors-education partners aiming to advance teachers' professional development. Examples of these programs are: Advancement of Qualifications of Teachers Project, Capacity Building for Teacher Mentors, Re-Qualification of Pedagogical Student Graduates, and so on. So far, in- service training programs have not been part of the systematic policy of Teacher Professional Development (TPD). Rather, they were a need for the re-qualification of teachers in their teaching degree or in the new teaching strategies (MEST, 2015). With the new strategic documents in place, in-service training is expected to play a vital role in TPD, leading to teachers' career advancement (MEST, 2016). A professional portfolio is a required tool from the pre-service studies as it will present ideas, professional goals and the ways of achieving these goals in a period of time. It will help teachers to self-reflect on what they have learned and how to improve their professional practice. Reflecting on their accomplished work is significant for the role and the well-being of the activities that they should perform on campus and in internships. However, not all students find the portfolio relevant to their professional development. Junior students treat it more as a task that they should complete during their studies, whereas senior students understand the importance of the portfolio and view it as a tool that will help them to enhance the quality of their work and to promote continuous professional development. At the same time, senior students consider the portfolio as a way to achieve the goals that they set for professional development.

\section{Research methodology}

This research paper presents the current state of usage of portfolio as a tool for teachers' professional development in pre-service teacher training at the Faculty of Education of the University of Prishtina. The research was conducted using qualitative methodology. Interviews were organised with students and graduates of the Early Childhood Department-Faculty of Education, University of Prishtina. Students were randomly selected; every fifth student was selected for each year, while alumni were purposely selected due to their easier access and the possibility of their inclusion in this research. Five students were selected for each year of studies, starting with the second year of studies, third and fourth, as well as five graduates. A total of 20 respondents were included in this survey.

The interviews were organised with each student and graduate separately. Each of the interviews lasted approximately 45-50 min. Students and graduates have voluntarily participated in the interviews. The difference between sophomores and third- and fourth-year students was that sophomores felt more limited in giving answers due to their beliefs about the portfolio and its relevance reflection, while third- and fourth-year students felt more confident in giving answers since they already had a clear portfolio effect on their professional development as it was their reflection on the quality of the work they did. The graduates were clear about the importance of reflection through the portfolio. With the permission of students and graduates, all interviews were recorded and transcribed. The final transcription report was provided to the participants for verification and signature. By signing these reports, they have confirmed that 
their answers were correct and the meaning they wanted to give has not changed through these statements.

The research was conducted to answer the following research questions:

1. 'How will a portfolio help pre-service teachers in their professional development'?

2. 'How do pre-service teachers understand the importance of a portfolio at different stages of studies'?

3. 'What impact does pre-service teacher alumni portfolio have on instructors' employment'?

4. 'In what way does self-reflection orient pre-service teachers towards motivation for professional development'?

5. 'How does self-reflection affect in-service teachers for continuous professional development'?

6. 'How appropriate is the portfolio as a tool to develop self-reflection in preservice teachers'?

The questions asked in the interview were semi-structured and intended to obtain the students' opinions on the following:

- The importance of portfolio preparation and reflection for pre-service preschool teachers;

- The benefits of portfolio preparation;

- The portfolio's significance for professional development; and

- The portfolio's importance in employment.

\section{Research outcomes}

\subsection{The importance of portfolio preparation and reflection for pre-service preschool teachers}

Based on interviews regarding students' opinions on the preparation of portfolios, it is evident that learners had very different perceptions. Since the concept of portfolio creation is perceived differently by students, varying in various levels of study, second-year students are found to be more inclined to viewing it as a chore that should be checked off of their list of obligations;

"I spend a lot of time preparing my portfolio... it takes hard work."

Nevertheless, third-year students seem to understand its importance in their professional upgrading. They begin to consider portfolios as a useful tool which they will continue to use at their jobs even after graduation. A third-year student stated that:

"In the beginning, I thought it was not important but now it seems to be very helpful."

By contrast, fourth-year students or alumni do not view portfolios as a task but instead as a tool for summarising and evidencing works and professional ideas. Similar to the previous statement, a fourth-year student declared that:

"By using the portfolio, I know what I'm doing... selection of materials is important for ongoing development." 
Meanwhile, the alumni expressed that:

"The portfolio is a necessary tool as it helps to reflect on professional development."

Based on these answers, it can be concluded that the portfolio is seen as an exceedingly important tool, necessary for the ongoing professional development of graduates who have entered the teaching profession.

\subsection{The benefits of portfolio preparation}

There is a discrepancy between second-year students and other years students' opinions regarding the benefits of preparing a portfolio. A second-year student stated that:

"Portfolio helps me to get a good grade."

Meanwhile, third-year students stated that:

"The portfolio helps me recognise my weaknesses..."

This attitude is directly related to the reflection of the pre-service teacher related to his/her work. Through portfolios, students manage to self-evaluate their work and professional development. On the other hand, a fourth-year student notes the portfolio's importance as an opportunity for the development of critical and creative thinking. In this regard, she declares that:

"The portfolio helped me to be a critical thinker in my work and professional development. By using the portfolio, I can easily identify my strengths and my weaknesses."

Moreover, an alumni student considers portfolios as a tool that helps her to focus on completing her objectives. In this regard, she stated:

"The portfolio has helped me become more efficient, improve my quality of work in planning and my cooperation with colleagues."

Based on the statements provided by the students, it has been concluded that second-year students consider the portfolio as a means to achieve the highest grades, while third-year, fourth-year and alumni students view it as an essential implement for professional development. Their opinions have developed precisely from their experiences with portfolio preparation. Self-reflection on the professional development of pre-service teachers is more witnessed among the fourth-year students than the students of previous years. They have already realised the importance of reflecting on their work, and through this, they begin to make ongoing plans for their professional development. The reflection itself is even more emphasized among the graduates. Through statements, they have emphasized that through this form, they become more efficient and focus to a greater extent on the quality of their work. Reflections has allowed them to improve their professional practices and knowledge, thus making them better prepared teachers.

\subsection{The portfolio's significance for professional development}

Students have expressed the significant contribution of portfolios to their professional development as well as their reasoning behind it. Even in the case of 
second-year students, it is evident that their lack of experience makes them more inclined to consider portfolio as a task through which they can learn. At this level, they have not yet fully established the importance of portfolios in their personal and professional development. Therefore, by continuing to think that the employment of portfolios enables them to learn new things and compare their work with others, the portfolio becomes more appealing. A second-year student declared:

"I do research so that I can have a good portfolio, which in return will help me improve my work. The portfolio also helps me to compare my work with others."

Meanwhile, the opinions of third-year students begin to present a higher level of advancement regarding the importance of portfolios in their professional development. Hence, third-year students are more inclined to consider it as an encouraging tool for cooperation with others and as something that helps them feel secure. In this regard, a third-year student stated:

"The portfolio has helped me to cooperate with others. Cooperation is a job-requested skill..."

In contrast to the second and third-year students, the opinions of the fourth-year students hold the portfolio as a source of new ideas, an instrument that provides them with security, and more importantly, an opportunity for self-evaluation. A fourth-year student declared:

"The preparation of portfolios has given me more confidence and I do better quality work. I am more confident in what I do"

This allows for a better understanding of the fourth-year students' view because through their experience, whether they have been taught on campus or internships, they have found the portfolio to have a significant impact on their preparation for the teaching profession. Therefore, their opinions at this stage are also more constructive and based on the achieved results. Meanwhile, graduates see the importance of the portfolio as an evidence of their qualitative work with which they can secure their job more easily, which encourages them to apply this kind of assessment with the children involved in their work. In this regard, an alumni declared:

"The portfolio is the summary of my work. Additionally, the portfolio has enabled me to get a job at a private preschool."

Based on the students and alumni's answers, we can conclude that portfolios are a critical tool in the professional development of pre-service teachers. By using portfolios, pre-service teachers understand goals and ways to achieve those goals. The portfolio is a testimony of the acquired knowledge and skills of pre-service teachers, which consequently enables them to focus on their professional development.

\subsection{The portfolio's importance in employment}

Due to the portfolio being one of the most important tools for their professional development, students have shared their opinions on the importance of the portfolio in their employment phase. This question has been answered by third- 
year students, fourth-year students and alumni since their chances of obtaining a job are higher than those of second-year students. The students have described their opinions about the professional preparation that they have achieved through the development of portfolios. They explained how much the preparation of portfolios has helped or will help them to find employment in their professional field. Third-year students have said that the portfolio has helped them to love their future profession and at the same time has helped them to develop presentational skills. As a result, they can better present their work, and according to them, these are the benefits that will give them advantage over others. One of the opinions of the third-year student in this regard was:

"The portfolio has helped me to further develop my presentational skills as I had to present my work. It has helped me to love my future profession more..."

A fourth-year student stated that throughout the portfolio preparation process, they are taught to organise and document their work, which is of great advantage to all those who work. The student also said that developing portfolios requires creativity and the use of new ideas and different materials, especially those that are recycled so that the portfolio is more meaningfully presented to others.

"The portfolio helped me understand that it is necessary to be organised at work... Portfolio preparation pushed me to be more creative and to use recycled and reusable materials."

Given the above-mentioned characteristics, students are convinced that they will find jobs more easily since those aspects are required in the first interview. Graduates have stated that during their studies, in certain cases, they did not consider portfolio as useful work. However, when they applied for work, they realised that a portfolio is an extraordinary tool used to present their professional preparation:

"In the beginning, I thought I am doing work that nobody appreciates, but now I see that the portfolio is an amazing testimony. Each time I look at my portfolio, I feel like a teacher, and I will create a portfolio for my preschool students."

Based on the interviewers' opinions, we can conclude that the portfolio also plays an important role in pre-service teacher employment. Through portfolios, preservice teachers can easily prove their professional development and present their work to children. It is of utmost importance that they apply the same kind of assessment to pre-school children; the application of formative assessments and the documenting of the level of childhood achievement. Furthermore, they are able to document the ideas, approaches and goals related to their teaching profession.

\section{Conclusions}

According to the research data, portfolio is a siginificant factor in educators' professional development. This instrument provides future teachers with the opportunity to learn to self-reflect and to simultaneously organise their work better. To create skills in view of collaborating with others directly and to reflect 
by analysing and comparing the work of each-other affect the development of professional competencies for teachers.

Furthermore, through the literature review and the results of the research, it is noted that the preparation of portfolios enables students to self-evaluate their knowledge, their skills and the need for further professional development and to assess others' work. Through self-evaluation, learners can advance their approach and achieve a high level of professional performance. Using feedback and reflection to modify teaching practice in the early stages of one's career as a teacher educator is a fascinating and fruitful process (Hamilton, 2018). We also note that portfolios increase pre-service teachers' self-confidence, which improves their quality of work.

Portfolios develop creative and critical thinking, decision-making skills and communication and presentation skills since one must present one's work to others and receive and give feedback. As a result, teachers become prepared and competent for their future assignments. They would have benefited from a group discussion about the school's strategy work as well as a brief reflection on the lessons learned (Körkkö et al., 2020).

Besides, a teacher who has prepared his/her portfolio is interested in doing the same thing with children. Documenting children's development is important and highly appreciated by parents. Also, encouraging children at a young age to reflect on themselves and their work instructs them to think critically and creatively. Consequently, they will employ a more positive approach to themselves and others.

\section{References}

Baumgartner, P. (2009). Developing a taxonomy for electronic portfolios. Studien Verlag.

Beka, A. (2015). Sustainability in higher education: Linking teacher education with labor market in Kosovo. In J. P. Filho (Ed.), Challenges in higher education for sustainability (p. 189-197). Springer. https://doi.org/10.1007/978-3-319-23705-3_8

Beka, A., \& Gllareva, D. (2016). The importance of using electronic portfolios in teachers work. Applied Technologies and Innovations, 12(1), 32-42. http://doi.org/10.15208/ati.2016.03

Belgrad, S. F., Burke, K. B., \& Fogarty, R. J. (2008). The Portfolio Connection: Student Work Linked to Standards (3rd ed.). Corwin.

Ciesielkiewicz, M. (2019). The use of e-portfolios in higher education: From the students' perspective. Issues in Educational Research, 29(3), 649-667. http://www.iier.org.au/iier29/ciesielkiewicz.pdf

Cimermanová, I. (2019). Teaching portfolio as a source of pre-service teacher training programme needs analysis. Pedagogika, 131(3), 201-216. https://doi.org/10.15823/p.2018.42

Dilger, B. (2007). Der selbstreflektierende lerner [The self-reflective learner] (1st edition). EuslVerlag, Paderborn, Germany.

Driessen, E. (2017). Do portfolios have a future? Advances in Health Sciences Education: Theory and Practice, 22(1), 221-228. https://doi.org/10.1007/s10459-016-9679-4

Faculty of Education. (2013). [Fakulteti i Edukimit]. https://edukimi.uni-pr.edu/ 
Fernández, D. M. (2014). "Integrating the European portfolio in a competency-based teacher education approach". In English as a foreign language teacher education, (Vol. 27, pp. 35-38). Brill | Rodopi. https://doi.org/10.1163/9789401210485_005

Häcker, T. (2009). Wurzeln der Portfolioarbeit [Roots of portfolio work]. In T. H. I. Brunner (Ed.), Das handbuch portfolioarbeit [Portfolio handbook] (pp. 27-32). FriedrichVerlag

Hamilton, M. (2018). Bridging the gap from teacher to teacher educator: The role of a teaching portfolio. Studying Teacher Education, 14(1), 88-102. https:// doi.org/10.1080/17425964.2017.1414041

Henderson, J. L., Davis, R. R., \& Day, T. M. (2015). Developing Portfolios to Document Student Performance and Accomplishments. NACTA Journal, 59(4), 350-353.

Jones, M., \& Shelton, M. (2011). Developing your portfolio enhancing your learning and showing your stuff. Routledge.

Kayler, M. A. (2004). Portfolio assessment and teacher development. Academic Exchange Quarterly, 8(3), 265-274.

Kerr, R. (2007). Portfoliomappe Selbstdisziplin [Portfolio self-discipline]. Beltz Verlag.

Körkkö, M., Kotilainen, M.-R., Toljamo, S., \& Turunen, T. (2020). Developing teacher inservice education through a professional development plan: modelling the process. European Journal of Teacher Education, 1-18. https://doi.org/10.1080/02619768.2020.1827393

Lynch, M. (2000). Against reflexivity as an academic virtue and source of privileged knowledge. Theory, Culture and Society, 17(3), 26-54. https://doi.org/10.1177/02632760022051202

Martin-Kniep, G. O. (1999). Capturing the wisdom of practice: Professional portfolios for educators. Alexandria, VA: Association for Supervision and Curriculum Development.

McKimm, J. (2014). Assuring quality and standards in teaching. In H. Fry (Ed.) A Handbook for Teaching and Learning in Higher Education: Enhancing academic practice (4th ed.). Routledge.

MEST (2011). Ministry of Education Science and Technology. Law on higher education. https:// masht.rks-gov.net/en/legjislacioni

MEST (2015). Ministry of Education Science and Technology. http://masht.rks-gov.net/

MEST (2016). Ministry of Education Science and Technology. http:/ / masht.rks-gov.net/

Paris, S. G., \& Ayres, L. R. (1994). Psychology in the classroom: A series on applied educational psychology. Becoming reflective students and teachers with portfolios and authentic assessment. American Psychological Association. https://doi.org/10.1037/10158-000

Riebenbauer, E., Dreisiebner, G., \& Stock, M. (2017). Providing feedback, orientation and opportunities for reflection as key elements for successful mentoring programs: Reviewing a program for future business education teachers. Global Education Review, 4(4), 54-69. https://ger.mercy.edu/index.php/ger/article/view/255

Slepcevic-Zach, P., \& Stock, M. (2018). ePortfolio as a tool for reflection and self-reflection. Reflective Practice, 19(3), 291-307. https:/ / doi.org/10.1080/14623943.2018.1437399

Stock, M., \& Winkelbauer, A. (2012). ePortfolio-implementation in the master's program of business education and development. International Journal of Business Education, 152, 48-55. https://www.ijbe.online/2012-eportfolio-implementation-in-themasters-program-of-business-education-and-development.html

Trávníčková, P., \& Puhrová, B. P. ů. (2019). Professional Portfolio of the Preschool Teacher: What Is the Real Content? Advances in Intelligent Systems and Computing, 156-162. https://doi.org/10.1007/978-3-030-20135-7_15 
University of Prishtina. (2004, 10, 21). [Universiteti i Prishtines]. https://edukimi.unipr.edu/

Webster, R. S., \& Whelen, J. D. (2019). The Importance of Rethinking Reflection and Ethics for Education. Rethinking Reflection and Ethics for Teachers, 1-12. https://doi.org/10.1007/978-981-32-9401-1_1 